\title{
Segregation and daily mobility, an international comparison
}

\author{
E. Ravalet \\ Laboratory of Transport Economics (LET), Lyons University, France \\ National Institute of Scientific Research, Urbanization, Culture and \\ Society (INRS-UCS), Montreal, Canada
}

\begin{abstract}
While there is a great deal of literature on the socio-economic specialization of residential spaces, little has been written about the other spaces of the city that articulate citizens' daily lives. This paper examines urban segregation through the lens of individual everyday mobility in three cities: Lyons in France, Puebla in Mexico and Niamey in Niger. This comparison serves to highlight particularly strong trends that structure everyday patterns of activity and use of urban spaces (despite important differences of the modal shares). Between choices and constraints, citizens move in spaces that differ according to demographic, economic and geographic features. The latter are dealt with in transport household surveys carried out in each city, on which our research method is based. Urban areas of each city were selected and behaviors of individuals were studied in terms of activities and daily mobility. The study pursues two purposes: the characterization of individuals' travel-activity patterns and the description of the relationship of these patterns to a large range of variables (individuals' and households' characteristics). Transport and activities behavior vary greatly according to the particular social group under study, partly because of their unequal access to means of transport. Constraints related to social and economic status are particularly relevant in explaining these differences. Gender also appears to be a central factor in the analysis of segregation in some neighborhoods of Puebla, Lyons and Niamey. An original insight into urban segregation is finally obtained, based on individuals and on activities in space and time.

Keywords: urban segregation, daily mobility and activities, gender, Puebla, Niamey, Lyons.
\end{abstract}




\section{Introduction}

Urban segregation, considered as the separation of individuals from one another, is a common fact in contemporary cities. The literature, which is very abundant on the subject, usually limits itself to residential location. As mobility is an integral part of these same cities, we have decided to study the question of segregation in relation to inhabitant access to urban activities and areas. After having specified our theoretical position, we will tackle the case of three cities situated in different cultural contexts. Three strong tendencies will emerge from their study, which will be successively presented in the second part of this paper.

\section{Segregation through daily spatial dynamics}

\subsection{Urban populations and entre-soi}

The $20^{\text {th }}$ century was stamped by a growing urbanization in societies of the North as well as the South. The explosion in the size of cities was accompanied by widening reflection on the urban phenomenon as a subject of sociology. One striking definition of the city was given by L. Wirth [1]: " a city may be defined as a relatively large, dense, and permanent settlement of socially heterogeneous individuals". This social diversity is geographically defined as residential groupings, which Chicago sociologists would extensively describe. It is well known through the term of urban segregation.

It clearly emerges from numerous studies carried out on the subject that residential practices tend towards entre-soi [2], in the cities of the North as in the cities of the South. Without any negative connotation a priori, this notion refers to a will on the part of urban residents to remain within their own social group. They aim for a certain social proximity with those they mix with on a daily basis. The notion of entre-soi can be seen in working class suburban areas, in gated communities, in Chinatowns, artist quarters, gay villages, etc. In certain cases the poorer inhabitants have no other choice than to stay in their neighborhood (thus creating a segregation situation); and in other cases one may speak of a willful separation concerning the wealthiest and the poorest [3]. Places of residence are therefore sometimes chosen, sometimes endured, depending on the strength of constraints weighing on the urban residents in question.

V. Kaufmann [4] believes that the fragmented contemporary city is made up of worlds whose inhabitants meet very little, because of a collision in speeds and spheres of daily life. This statement suggests the existence of segregation in urban spaces that goes beyond that of residential locations. The notion of entresoi does not only concern housing. The analyses carried out on certain neighborhoods show the need to go beyond the classical approach, which considers segregation only through urban resident housing. It would be fitting, on the contrary, to privilege an approach that considers diverse spatial practices and uses of the city for different population categories [5]. 


\subsection{Daily town life, activities and mobility}

"Individuals generate extremely complex travel-activity patterns as they participate in daily activities at different times and in different locations" (Hanson and Hanson [6]). We consider that the questions of entre-soi should be tackled in the light of individual behavior and in terms of mobility and activities. Daily travel is thus a tool that is adapted to this type of reasoning. It helps in the understanding of individuals' activities, the areas that group them and the modes of transport used. The perspective is thus multiple as it throws a certain amount of light on life styles while offering information on the use of the city. We concentrate our study on daily behavior that we consider as incorporated habit, the fruit of experience acquired by the players. The choice of a study on daily mobility means, placing the individual at the heart of the approach. Limiting oneself to residential spaces for the study of segregation is in fact limiting oneself to households thereby ignoring the wealth of a study based on the individual. This is why we aim at a dialectic consideration of the individual and his environment (physical and social).

Travel modes should be considered more at length here. According to G. Amar [7], they are sociotechnical items resulting from a stable, sound combination of socioprofessional and sociocultural material elements. This definition suggests a necessary differentiation between technical items that are similar but situated in different socioprofessional and sociocultural contexts. The mode of transport corresponds to an interface between the citizen and his city and each implies a specific relationship with the city. G. Amar [7] develops the concept of urban adherence of travel reconsidering mobility in relation to space. Interaction between places and activities of a city is thus broached. The car is strongly linked to the periphery and walking is linked to the city centre (a dense environment in which activities are easily accessible without a vehicle). Our objective is to point out that the shape of a conceived framework may be associated with the use of specific trip modes. Depending on the mode used, urban residents do not have the same relationship with their adjoining physical and social environment.

\subsection{Differences and inequalities, from theory to method}

Through this study, and the understanding of mobility behavior and individual activities, it is important to consider lifestyles and their variability within an urban population. Lifestyle is considered in this study as a "pattern of behavior which conforms to the orientation an individual has to the roles of family member, worker and consumer of leisure and to the constrained resources available" (Salomon [8]). The explicit reference to constraints weighing on the individual is emphasized. "Constraints on travel can be imposed by a person's social or economic status, by one's household and societal roles, or by one's location vis-à-vis the transport system and activity sites" (Salomon [8]). Urban residents effectively find themselves within a system of choices and constraints that participate in lifestyle building, the constraints functioning as borders which limit individual behavior in space and time [9]. When these constraints are too 
strong the individuals concerned may find themselves in situations of social exclusion as described by T. Litman [10]. "Social exclusion refers to constraints that prevent people from participating adequately in society, including education, employment, public services and activities. Inadequate transport sometimes contributes to social exclusion (...)". Inequalities in access to services and urban functions are partly relayed by the different access to trip modes. F. Ascher [11] hence speaks of transport as a factor of social injustice.

The variability of constraints weighing on each person is therefore a source of inequalities between individuals, but one must be careful not to confuse inequalities and differences. Differences may become inequalities when, on the whole, they reflect systematic discrimination against a large identifiable group. This group can be identified through, for example, ethnic origin, gender, age or socio-economic conditions [12]. The aim is therefore to be able, whenever possible, to interpret differences in transport behavior and situate the groups concerned to be in a position to speak of inequalities.

The study of each of these cities was carried out in two stages. An attempt was made to characterize differences in behavior between individuals on the basis of their mobility and their activities. Then we attempted to explain these differences. As I. Salomon points out [8], life styles are "determined by two exogenous factors: the social context and the personality attributes". The variables that have been chosen for this study imply these two dimensions. Socio-professional category, income, residential location, number of people per household, occupational status and type of housing correspond to the social context. Age, gender, status, role within a household, etc. correspond to individual characteristics. Our study is based on household trip surveys carried out in three different cities in the mid 1990s.

\subsection{Three cities for three contrasting visions}

Three cities are studied in this paper: Lyons (France), Puebla (Mexico) and Niamey (Niger). This choice was made through a wish for strong variability in modal share specific to each town (figure 1). The cultural contexts are also very different, which means that care must be taken when drawing parallels. Through these specificities, we have looked for three contrasted visions on the question of entre-soi in daily activities.

Each city will now be described to better understand the challenges they offer. To the North of the Rhône-Saône confluent lies Lyons [13] which is a main French city. To the east of the historical centre, the business quarter has grown around the TGV train station: la Part-Dieu. In the near east of the agglomeration, in Vaulx-en-Velin, Bron as well as in Rillieux-la-Pape, high rise apartment blocks have been built regrouping a low-income population. Large peripheral spaces come next, home to individual houses and cars (pendular trips are made over a zone of nearly $45 \mathrm{~km}$ around Lyons [14]). It is to be underlined that the west of the agglomeration, which is traditionally less industry focused, today regroups populations who are among the wealthiest. In 1999, the number of inhabitants in the agglomeration reached 1.165 .000 , growing but slowly. 

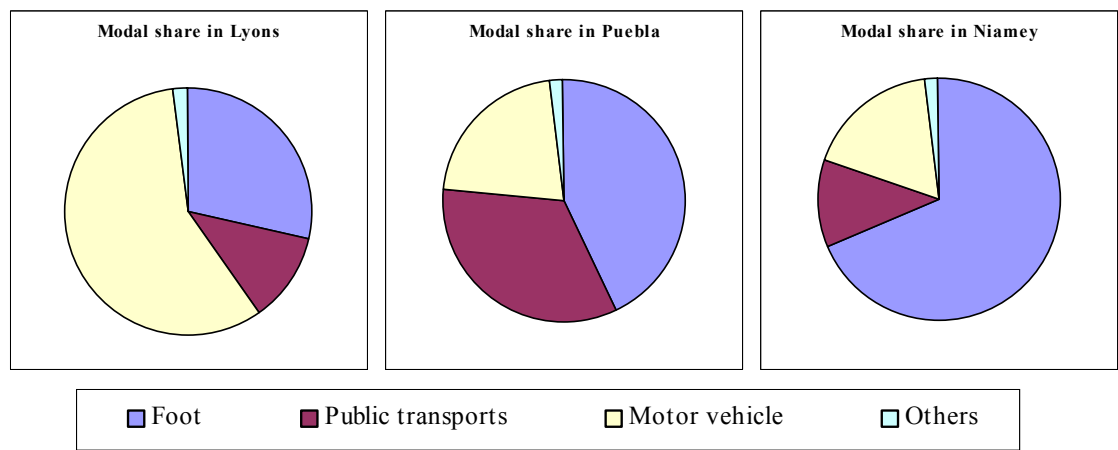

Figure 1: Modal share in Lyons, Puebla and Niamey.

The city of Puebla, the forth most populated city in Mexico, was founded in the 16th century by the Spanish who applied the principal of orthogonal development by spreading towards the four cardinal points [15]. Situated two hours by road from Mexico, this ancient colonial city lies on the Mexico/Veracruz axis, which makes it an important industrial centre with a strategic position. A tertiary economy is developing but still remains relatively weak to this day. Puebla today boasts a large university and, a historic centre which is known for its heritage but has relatively few major cultural facilities. In 2003, the agglomeration reached 2 million inhabitants [16].

The city of Niamey is by far the most recent. Settled on the banks of the Niger River, this old colonial city was but a village at the beginning of the 20th century. Its development came in step with extremely rapid demographic growth. Rural exodus played an important role there, especially during periods of drought. Today the city counts nearly 700,000 inhabitants [16]. It revolves around the centre and its 3 markets (main market, small market and Katako market). Non-parceled outer peripheries are continuing to grow, with low accessibility to activities. It should be noted that only the Kennedy Bridge allows the river Niger to be crossed, while the city is also spreading Arrobanda (across the river).

This paper aims at offering three perspectives to one same debate. The aim is to weigh the strong behavioral trends of the urban residents in each city.

\section{A different view of urban segregation}

Overall results indicate three strong trends. We shall begin with the effects of income on the town focus of urban residents.

\subsection{From neighborhood to city: a question of means}

Literature concerning mobility considers income as a key variable in the study and understanding of travel patterns. "Within any specific society, mobility 
increases with income. This may be called a universal phenomenon, regardless of geography and social conditions" (Vasconcellos [17]).

When economic constraints are too strong, urban residents cannot travel as much as they would wish. Weakness in revenue means few households have private vehicles. In terms of trips and activities the less well off travel less frequently, less far and when necessary. Those living in the suburbs of Lyons have restrained conditions of mobility compared to other inhabitants of their city. In Niamey and Puebla, these situations of neighborhood confinement concern the underprivileged urban residents of the outer periphery zones. Distances covered by these populations are greater and trip conditions are difficult. Lazaret in Niamey is an example. Inhabitants do not leave their neighborhood unless they have to; either to go to work or visit their acquaintances (sociability networks offer multiform help but are accompanied by a certain number of duties including frequent visits [18]). The few activities and the weakness of solidarity networks within the neighborhood force these populations to do so quite frequently (figure 2). It is worth noting that adherence of travel there, is very low, (they are made on foot while the urban form is ill adapted). These urban residents are in fact forced to stay in the neighborhood or are constrained in the city [19].
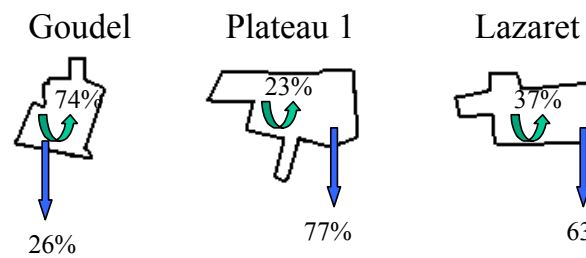

Figure 2: $\quad$ In and out trips in three different areas of Niamey.

In Niamey, certain underprivileged urban residents are in an atypical situation. These are populations who live in former villages that the city has caught up with. Goudel is one example. Life-styles have remained surprisingly rural and one may encounter cattle and all sorts of activity including agriculture, breeding, small commerce and schools, etc. As with underprivileged central residents their limited mobility is less problematic than that of other peripheral urban residents particularly thanks to the smooth running of a non-monetary economy. Their integration in a large city is only slowly changing their lifestyles and their relationships to space.

Activities and trips of the underprivileged strongly contrast with the wealthier urban residents. The inhabitants of The Plateau in Niamey generally have cars; those of $L a$ Paz in Puebla and the XI eme arrondissement in Lyons are characterized, despite relative proximity to the centre of their town, by high vehicular mobility. As the literature points out "Those with higher incomes make more vehicular trips per day, undertake more social trips, and travel greater distances to shop" (Hanson and Hanson [6]). Trip motives are also more diversified. It is to be noted that wealthy "Puebla" urban residents travel 
particularly often to the city centre which underlines its importance and attraction within the agglomeration (drivers, who choose their destinations are a good indication of the relative area attraction of areas).

The case of urban residents in the Ouest-Lyonnais (a wealthy periphery) should be evoked here. They have only little contact with their local environment. Practically all motorized, they carry out long trips to access their daily activities. While underprivileged peripheral urban residents in Niamey and Puebla live in the city but do not benefit from the advantages that this could procure them, the wealthy populations of the Ouest-Lyonnais do not really live in the city but do take advantage of it. Only a private car allows this type of relationship with the city.

In this section, we have compared urban residents according to their neighborhood of residence. The issue suggests, however, that there are strong disparities within the same neighborhood. Noting individual statuses is very meaningful from this point of view.

\subsection{Urban statuses and their urban declination}

Although it is often underestimated in mobility pattern studies, the status variable is in fact central. Status corresponds to the role of the individual as described by S. Hanson and P. Hanson [6]: "An individual's role in the household as well as in the larger society is defined not only by participation in the labor force, but also one's age, sex, marital status, and stage in the life cycle". Examples of possible statuses for surveyed urban residents are: active, job seeker, inactive, schoolchild, student, retired. These statuses are associated to different activity needs, to variable aspirations and constraints [6]. They may be classed therefore in terms of trips and activities. When constraints are heavy, urban residents limit themselves to the various trips imposed by their status and their relationship to the city.

Very generally speaking, it may be noted that when urban residents acquire financial independence, they adopt an urban lifestyle and diversify their activities. Urban resident behavior in the three cities shows that the less the individuals are wealthy the stronger the constraints linked to their status. It seems that the mobility of actives has priority over those of the other members of the household and that the transport budget is allotted to them first. The other members of the household may then find themselves without any means of transport, confined to home if the distances to cover for access to activities are too extensive. This trend can be seen in the underprivileged areas mentioned in the preceding section.

In Puebla, spatial constraints are strong and actives spend a lot of time commuting. They have little parallel activities; especially the underprivileged peripheral populations. Public transport does permit unequipped individuals to cover long distances but this takes a long time. (Trips in public transport are, on average, nearly twice as long as trips in private cars).

A specificity appears regarding Niamey school children and students. Despite little means and strong spatial and economic constraints, their travel behavior is dynamic with a definite town focus. One could immediately think of a generation 
effect, considering that the young inhabitants of Niamey are considerably more mobile than their parents were at their age. Unfortunately we have no means to verify this. However age associated to statuses may explain certain trends, which is the case for older people being confined to their neighborhood [20].

\subsection{Men and women in an urban context}

Remaining within an individual dimension of urban segregation, it is important to specifically tackle the question of gender. Women are ever more mobile and intergenerational differences are sometimes very noticeable [21]. Documentation on western female mobility also refers to shorter trips, increasingly complex trip chaining and an increasingly balanced ratio in male/female motorization [22]. Also found in the literature is that despite generational evolutions, "Women travel less than do men, even when employment status is controlled, women travel shorter distances than do men, shop more than men, and rely on the bus and pedestrian modes to a far greater extent than do men" (Hanson and Hanson [6]). Beyond these generalities, the difference in the position of women, according to these cultural and social contexts, shows highly contrasted tendencies.

In the Lyons agglomeration, differences in male and female activities may be seen in large high-rise apartment blocks in the "banlieue". There, women travel a lot less than men do, often within the neighborhood and for household linked motives such as shopping and accompanying children. In these areas there are more children on average than in the rest of the Lyons agglomeration. Associated organizational constraints are even stronger as these populations have lower incomes. The distance to work for men and the impossibility of bi-motorization therefore reduces female mobility.

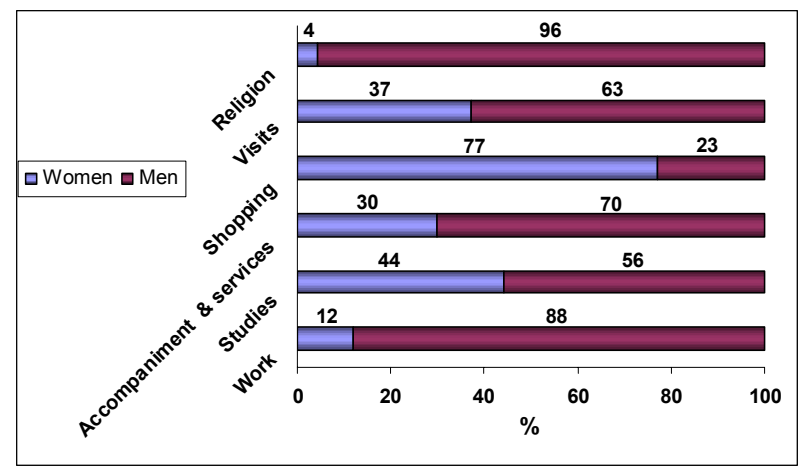

Figure 3: Distribution of activities according to gender in old peripheral villages of Niamey.

This distribution of tasks in male and female activities can be seen throughout the agglomerations of Puebla and in Niamey, where differences are intensified (figure 3 ). It should be noted that women undertake $30 \%$ of accompaniment and service trips, those that take place within the neighborhood. The very strong 
presence of children and the importance of conjugal life on the one hand, the weight of tradition, including polygamy, and the Muslim religion on the other hand explain this state of affairs. Furthermore it may be emphasized that the neighborhoods that are the most affected are the old villages overtaken by urbanization in Niamey.

\section{Conclusion}

By tackling the question of urban segregation by analyzing daily activities, certain significant trends have appeared. We may especially observe that women are more often involved in situations of segregation and that work creates links with the town. Tighter task distribution in households, among other factors, means that the poorer the urban residents are, the clearer their interindividual differences will be. Specificities that are particular to each context must not be left aside however. Diversity in cities, in neighborhoods and in populations who live there has allowed us to moderate our analysis. The city is not a universe of choice but a space of constraints and inequalities. Although everyone can observe a world map, world wide traveling is another question altogether. The same holds true at the urban scale.

\section{References}

[1] Wirth, L., Urbanism as a Way of Life. American Journal of Sociology, 44, pp. 3-24, 1938.

[2] Orfeuil, J.P., La mobilité: Analyses, représentations, controverses, thèse d'habilitation à diriger des recherches, Université Paris XII-Val de Marne, Institut d'urbanisme de Paris, 1999.

[3] Jaillet, M.C., A propos de la mixité. Les cahiers de la DSU, 21, pp.38-43, 1998.

[4] Kaufmann, V., Mobilité et vie quotidienne: synthèse et questions de recherche. 2001 Plus... Synthèses et recherches, centre de prospective et de veille scientifique, 48, pp. 1-64, 1999.

[5] Dureau, F., Les nouvelles échelles de la ségrégation à Bogota. Métropoles en mouvement, une comparaison internationale, ed. F. Dureau, V. Dupont, E. Lelièvre, J.P. Lévy \& T. Lulle, Economica, I.R.D., pp. 247256, 2000.

[6] Hanson, S. \& Hanson, P., The travel-activity patterns of urban residents : dimensions and relationships to sociodemographic characteristics. Economic Geography, 57(4), pp. 332-347, 1981.

[7] Amar, G., Pour une écologie urbaine des transports. Les Annales de la Recherche Urbaine, 59-60, pp. 1-15, 1993

[8] Salomon, I., Life style as a factor in explaining travel behavior. Doctoral Dissertation, Dept. of Civil Engineering, M.I.T., 1980.

[9] Di Meo, G., Géographies tranquilles du quotidien. Les Cahiers de Géographies du Québec, 43(118), pp.75-93, 1999. 
[10] Litman, T., Social inclusion as a transport planning issue in Canada : Contribution to the FIA Foundation G7 Comparison, Victoria Transport Policy Institute, 2003.

[11] Ascher, F., Mobilités et temporalités dans les villes américaines, recherche DRAST et PREDIT,1998.

[12] Purwanto, A.J., Dynamique des inégalités entre les Franciliens face aux transport, thèse de doctorat en Sciences Économiques, Université Lumière Lyon2, 2004.

[13] Ville de Lyon, www.Lyon.fr

[14] Aguiléra-Bélanger, A., Bloy, D., Buisson, M.A., Cusset, J.M.\& Mignot, D., Localisation des activités et mobilité. recherche effectuée pour la D.R.A.S.T., L.E.T., 1999.

[15] Polèse, M., Pérez, S. \& Baragan, C., Estructura urbana interna y desarrollo national: la localizacion de la actividad economica en la ciudad de Puebla, Mexico. Cahier/discussion paper 5-94-E, Villes et développement, 1994.

[16] United Nations, www.un.org/esa/population/unpop.htm

[17] Vasconcellos, E.A., Urban transport, environment and equity, the case for developing countries. Earthcan, London, 2001.

[18] Marie, A., (ed). L'Afrique des individus, Karthala, 1997.

[19] Plat, D., Mobilités quotidiennes en Afrique subsaharienne. Dossier de candidature en vue de l'obtention de l'habilitation à diriger des recherches, Université Lumière Lyon2, 2003.

[20] Clément, C., Espaces de vie, espaces en ville. thèse de doctorat en Sciences Économiques, Université Lumière Lyon2, 2000.

[21] Spain, D., Gendered spaces and women's status. Sociological Theory, 11(2), pp. 137-151, 1993.

[22] Root, A. \& Schintler, L., Women, motorization and the environment, Notes and Comments. Transportation Research part D, (4), pp. 353-355, 1999. 